[Reprinted from PROC. ZOOL. Soc. LoND. Vol. 140, Part 1, pp. 61-74.] (Published February 1963)

A COLLECTION OF FISHES

FROM THE ASWA RIVER DRAINAGE SYSTEM, UGANDA BY

P. H. GREENWOOD

British Museum (Natural History) 



\title{
A COLLECTION OF FISHES FROM THE ASWA RIVER DRAINAGE SYSTEM. UGANDA
}

\author{
$\mathrm{BY}$ \\ P. H. GREENWOOD \\ British Museum (Natural History) \\ [Accepted 13th February, 1962] \\ (With 1 figure in the text)
}

The Aswa river, a major tributary of the Nile, has its origins near Lake Kyoga, from which it is separated by a low watershed. The fishes described are the first to be collected from the Aswa. Two surprising features of the fish fauna are an endemic Synodontis species and an endemic and phyletically isolated species of Haplochromis. . Despite the presence of several Nilotic species absent from the Kyoga-Victoria systems, the overall relation. ship of the Aswa species is with Lakes Victoria and Kyoga. It is suggested that the Aswa was once an affluent of Lake Kyoga.

\section{CONTENTS}

Introduction ..

Specimens collected..

61

Discussion

62

Acknowledgments

References

72

73

73

\section{INTRODUCTION}

The collection described below was made in April 1960 by the Uganda Game and Fisheries Department, and came from tributaries of the upper Aswa river about 20 miles north of Soroti. The Aswa rises on high ground in the western region of Karamoja and joins the Nile about 30 miles north of Nimule. For part of its course the river flows close to Lake Ky oga and some of its tributaries in this area arise near streams draining into Kyoga. Thus, it is an area of some zoogeographical interest since, like Lake Albert, it can be looked upon as an incursion of the Nile into a zone characterized by the large number of endemic or geographically restricted species occurring in bodies of water isolated both from one another and from the Nile.

Surprisingly, no other collection has been made from the Aswa so that until now we have been ignorallt of the nature of its fish fauna. This collection goes part-way to remedy the situation. But unfortunately it was made too late to provide an absolutely certain indication of the zoogeographical relationships of the fishes. Already several non-endemic cichlid species have been introduced in surrounding dams and the Game Department think that some of these may have escaped into the Aswa system. Also, with any introduction of a particular species there is the risk that other species may be introduced unwittingly. Because of these possibilities one cannot use the Tilapia species in this collection as evidence in a zoogeographical argument, particularly since 
at least four species have been introduced into dams on the Aswa side of the watershed.

Nevertheless, there are other fishes in the Aswa which can almost certainly be considered as natural elements of the fauna. These provoke intriguing thoughts on both the past and present drainage relationships of the river.

\section{SPECIMENS COLLECTED}

\section{MORMYRIDAE}

\section{Mormyrus caschive Linn., 1757}

A single specimen, $15 \mathrm{em}$. S.L. (immature female). Other records for the species in Uganda are from Lakes Edward, George, and Albert; the Albert and Murchison Niles.

\section{Mormyrus macrocephalus Worthington, 1929}

To date, this species has been recorded from the Lake Kyoga system, the Victoria Nile and since the construction of the Owen Falls Dam, from Lake Victoria itself (Greenwood, 1958). There are seven specimens (15'5-28'5 em. S.L.) in the Aswa collection; all are adult but none shows obvious signs of sexual activity.

Worthington (1929 b) noted the resemblance between this species and M. hasselquisti (from the Nile, Niger and Volta rivers) but differentiated M. macrocephalus on its longer head (3'5-4 times in standard length $c f .4,3-5,2$ times) the smaller scales around the caudal peduncle (30-34 cf. 26-30 in $M$. hasselquisti) and by its shorter and deeper caudal peduncle. The latter character is no longer valid since additional material shows continuous intergradation between the species. Another character, which Worthington did not consider, is the somewhat lower total number of dorsal fin rays found in $M$. macrocephalus. The ranges, however, show some overlap, that for $M$. macrocephalus being 64-70 and those for the Nile and Upper Niger populations of $M$. hasselquisti being 67-75 and 69-82 respectively.

On the sum of diagnostic characters, the Aswa fishes must be placed in M. macrocephalus. The head length is contained 4-4.3 times in standard length (it must be noted that the specimens are rather distorted), the range of dorsal fin rays is 62-71; and the caudal peduncle scale count is 30-34 (mode $32)$.

Undoubtedly, M. macrocephalus and $M$. hasselquisti are very closely related and I have suggested elsewhere (Greenwood, 1958) that they may be only subspecifically distinct. The problem is an interesting one since it seems impossible to distinguish between the Nile and Niger populations of $M$. hasselquisti, yet the geographically less separated Kyoga fishes are distinctive. Furthermore, although the Aswa river has direct continuity with the Nile, its population is recognizable as $M$. macrocephalus. This is explicable if it be accepted that the Aswa originally drained into the Kyoga system and acquired its Nilotic connection at a later date (see below, p. 73). Collections of $M$. macrocephalus-like fishes from the lower reaches of the Aswa should throw some light on the relationship of the two species. 
Gnathonemus cyprinoides (Linn.), 1764

Seventy-four specimens, 8.4-20.9 em. S.L. Other Uganda records for the species are from the Albert Nile only. The Aswa population seems to differ in its slightly smaller scales, particularly those in the lateral line series. In other meristic characters it is similar to populations from the Nile, Niger and Congo systems (I am most grateful to Dr Ethelwynn Trewavas for allowing me to use her unpublished data on these fishes).

Scale counts for the Aswa fishes (based on a sample of 25 specimens), are: Lateral line series: 76-92 (Mean 84).

Dorsal origin to lateral line: $15-17$ (in one specimen 13), mode 16. Anal origin to lateral line: 15-18, mode 16.

Scale index (sum of the three counts): 107-126, mean $=116$.

The fin ray counts are :

Dorsal 26--30, mode 27.

Anal 30-34 (modal range 33-34).

Hyperopisus bebe bebe (Lacépède), 1803

Five specimens, all juveniles, 16-19'2 em. S.L. In Uganda the species is otherwise only recorded from the Albert Nile.

Daget (1954) recognized two subspecies of $H$. bebe, the Nilotic form and a West African form. He distinguished the subspecies on fin-ray counts, caudal peduncle scales and certain body proportions. The Aswa fishes have dorsal counts overlapping both subspecies (12[f.IJ, 13[f.IJ and 14[f.3]) but the anal count agrees with the Nilotic subspecies. Likewise the caudal peduncle scale count is Nilotic (18[f.2J, 20[f.3J) as are the relative proportions of the head length and body depth: (Depth 4,8-5,3 in S.L., Head 4,8--5,1 in S.L.).

\section{CHARACIDAE}

Alestes macrolepidotus (C. \& V.), 1849

One specimen, a nearly ripe female, $18 \mathrm{em}$. S.L. Other Uganda records for the species are Lake Albert, the Albert Nile and the Murchison Nile.

\section{Alestes nurse (Riippell), 1832}

One specimen, a female nearly ripe, $14 \cdot 1 \mathrm{em}$. S.L. This species is closely related to A ..iacksoni of Lake Victoria (Greenwood, 1959) but I have no doubt as to the identity of the Aswa fish. The only record of A. nurse in Uganda was based on a few specimens (since lost) from Lake Albert collected by the East African Freshwater Fisheries Research Organization. Alestes nurse is common in other regions of the Nile.

\section{Alestes sadleri BIgI'., 1906}

ine specimens, aU adult and sexually active, 4'6-7 em. S.L. ; the smallest fish is a male, the others all females. Alestes sadleri is otherwise known only from Lakes Kyoga, Victoria and Nabugabo, the Victoria Nile and the Malawa river. The Aswa population does not differ in any respect from populations in other parts of Uganda. 


\section{CYPRINIDAE}

Labeo victoria-nus BIgr., 1901

Five specimens, 9,7-13,7 em. S.L., all sexually active.

This species was considered a Victoria-Kyoga endemic and it is therefore of interest to find it and not a Nilotic species in the Aswa drainage system. The specimens came from dams on tributary streams north of Kuju.

Barbus perince Riippell, 1837

Nine specimens, 5,7-7,7 em. S.L., all adult and sexually active. This species has a relatively wide distribution in Uganda and the Nile (Kazinga Channel, Lake Edward; Lake Albert; Remliki river; White Nile).

\section{Barbu8 kerstenii Peters, 1868}

Fifty-two specimens, 2,7-5,6 em. S.L., including juveniles and sexually active adults.

The species is very widespread in eastern Africa (Greenwood, 1962) and occurs throughout Uganda. It has not been recorded from the Nile.

\section{Barbus paludinosus Peters, 1852}

Fifteen specimens, 5·6-7,4 em. S.L., all adult and sexually active. This is one of the most widely distributed species in eastern, central and southern Africa, although it is not recorded from the Nile, Lake Albert, or Lake Kyoga. No clear-cut subspecies can be recognized but various populations of $B$. paludinosus may be recognized by the relative length of the third unbranched dorsal ray. The Aswa fishes differ from the geographically nearest known population (that of Lake Victoria) in having a slightly shorter third ray (20'7-26'9, mean 22.9 per cent of S.L., compared with 21.6- $28 \cdot 7$, mean 24.5 per cent). The difference is slight and may be due to the smaller size of the Aswa specimens.

\section{Barbus amphigramma BIgr., 1903}

Six specimens, 4.2-5.4 cm. S.L., all adult and sexually active.

The species is closely related to and often confused with $B$. paludinosus. In Uganda it is apparently restricted to the affiuent rivers and streams of Lake Victoria and the streams on Kadam Mountain (eastern Karamoja).

Barbus apleurogramma Blgr., 1911

Four specimens, 2,4--3,1 cm. S.L., sexually active adults. This is another widely distributed Barbus species (Greenwood, 1962), common in the VictoriaKyoga drainage basin but apparently absent from the Nile and Lake Albert.

Barbus yongei Whitehead, 1960

Twenty specimens, 3,1-4,4 em. S.L., all sexually active. The distribution of this species is apparently confined to the Victoria-Kyoga drainage basin (Lake Victoria i Nzoia and Malawa rivers). 
Barbus cercops Whitehead, 1960

Eight specimens, 3·2-4,8 em. S.L., all sexually active. Like B. yongei, the known distribution of this species is confined to the Victoria-Kyoga basin (Nzoia and Malawa rivers).

\section{Barbus (Beirabarbus) radiatus Peters, 1853}

Twenty-one specimens, 4.4-7.4 em. S.L. The adult fishes show some signs of sexual activity but the stage of gonad development is less advanced than in most other Barbus from this collection.

Note on nomenclature: In my paper of 1962 this species was named Barbus (Beirabarbus) doggetti Blgr., 1904. Recently I have been able to examine the two syntypes of Barbus radiatus Peters, from the collections of the Berlin Museum. One of these specimens (that figured by Peters [1868] in Reise nach Mossambique, 4, pI. 10, fig. 3) is undoubtedly a member of the Beirabarbus subgeneric group, and I can find no characters which would distinguish it from $B$. (B.) doggetti. A full account of this specimen (now considered the lectotype) and the status of the paralectotype will be published elsewhere.

The species is widely distributed in eastern Mrica but is not known from the Nile or Lake Albert (Greenwood, 1962).

\section{Barilius loati Blgr., 1901}

One specimen, $17.5 \mathrm{em}$. S.L., a sexually quiescent male. This is the first record of the species in Uganda, where the genus is represented (in Lake Albert) by Barilius niloticus. Barilius loati is recorded from the Lower Nile, Bahr-el-Gebel, the Blue Nile, Omo river and from West Africa.

\section{BAGRIDAE \\ Auchenoglanis occidentalis (C. \& V.), 1840}

Eight specimens, 12,8- 27,5 em. S.L. A female (23 em. S.L.) is ripening but the sexual state of the others (all males) could not be determined.

The species is widely distributed, but in Uganda is restricted to Lake Albert and the Murchison and Albert Niles.

\section{SCHILBEIDAE \\ Schilbe mystus (Linn.), 1762}

Sixty-seven specimens, 6'7-21 em. S.L. Many individuals are immature but the adults are all sexually active. All the specimens show the three dark longitudinal bands usually characteristic of juvenile fishes.

Schilbe mystus is widespread in Uganda and the Nile.

\section{CLARIIDAE \\ Olarias alluaudi Blgr., 1906}

One specimen, an adult and sexually active male, 8.6 em. S.L. The species is fairly widespread in Uganda and is recorded from the Victoria-Kyoga basin but not the Nile or Lake Albert. 


\section{Clarias mossambicus Peters, 1852}

Three immature specimens, 9,9, 17 and 23 ems. S.L.

The smallest fish has no food in the stomach but the stomachs of the two larger individuals are filled with numerous fish embryos and some plant debris.

The embryos are about $2 \mathrm{~mm}$. in length, the yolk oval in outline and bright yellow in colour; there is no indication of an adhesive disc or area on the chorionic membrane. Two ontogenetic stages are represented in the contents from each stomach viz. an early blastodisc stage and early embryos of about 14 somites.

I am unable to identify these embryos. Certainly their size, colour and shape eliminate any cichlid species, or the species of Clarias known to occur in the area. My colleague, M1' P. J. Whitehead, who has an extensive knowledge of the eggs and embryos of Lake Victoria Cyprinidae, is certain that the embryos are not cyprini.ds. Neither do the embryos resemble those of Marcusenius (Greenwood, unpublished) or those described for an Indian mastacembelid, Mastacembelus pancalus (,Tob, 1(41).

Because the embryos show a restricted range of development and because of their large numbers and undigested condition, I suggest that they were obtained from a single locality, probably a "nest". The small quantity of bottom debris present in the stomachs seems to support this idea.

\section{MOCHOKIDAE}

The only Synodontis in the collection are of an undescribed species:

\section{SYNODONTIS MACROPS sp. n.}

Holotype: an adult female 11.4 em. S.L. (Brit. Mus. (Nat. Hist.). reg. no. 1961.12.1.319 from a tributary stream ofthe Aswa river, Teso district, Uganda, collected by the Uganda Game and Fisheries department.

Description based on the holotype and six other specimens 9'7-12.6 em. S.L., all adults, reg. nos. 1961.12.1.320-5.

Depth of body 26-2-29.7 per cent of standard length, skin villose anterolaterally, smooth posteriorly. Head slightly longer than broad (1'12-1.23 times), rugose above. Humeral process acutely pointed, rugose-granulate and with a clearly demarcated, longitudinally striated keel; its length $44 \cdot 5-56$ per cent of head, 1.6--2 times as long as deep.

Snout rounded, as long as the postocular part of the head, 46,5-51,5 per cent of head length. Eye clearly snprolateral in position, its diameter contained $1 \cdot 3-1 \cdot 7$ times in the interorbital width, $24 \cdot 3-29 \cdot 8$ per cent of the head. Interorbital very slightly convex, its width $36 \cdot 4-45 \cdot 1$ per cent of the head.

Mouth -with deeply and densely plicate and thickened lips (moderately developed sensu Boulenger). Maxillary barbel with an ill-defined marginal membrane, its length 34.2-38.2 per cent of the standard length, 1.23-1.4 times as long as the head. Outer mandibular barbel with slender branches, its length about twice that of the inner mandibular and 79-92'5 per cent of the head. Inner mandibular barbels wi.th short, tuberculate branches on the anterior third (in one specimen, the anterior half), remaining branches slender hut short.

Gill openings not extending below the level of the pectoral fin. 
Moveable mandibular teeth slender, 18--21 in number, the transverse width of the band slightly less than half the diameter of the eye.

Dorsal fin I, 6 or 7 the spine slightly curved (almost straight), weakly rugose on the anterior face and weakly serrated posteriorly; its length 0'9-1'15 times as long as the head. The distal margin of the fin is damaged in all specimens but there are indications that the membrane between the spine and the first branched ray was produced into a filament and that there were filamentous projections from each of the branched rays. The distance from the snout tip to the origin of the dorsal fin is $40,5-44,8$ per cent of the standard length.

Adipose dorsal of varying development, its basal length 26,3-33,8 per cent of the standard length; the distance between the last dorsal ray and the adipose origin is contained 2.4-4.3 times in the basal length of the adipose.

Pectoral spine with small Lut distinct serrae on its anterior face and larger, stronger serrations on the posterior face, its length 26,2-29,4 per cent of standard length, about equal to the head length or slightly longer.

Ventrals of varying posterior extension, reaching or almost reaching the anal origin in five fishes, extending midway between the vent and the anal in one and reaching only to the vent in another ; there is no correlation with sex or sexual state.

Anal fin rounded, comprising 3(f.2) or 4(f.5) unbranched and 8(f.6) or 9(f.1) branched rays.

Caudal deeply forked, the upper lobe more prolonged than the lower and produced into a short filament.

Coloration (specimens fixed in .formol, preserved in alcohol).. Body light grey above, light brownish-grey ventrally;;' head and upper part of the hody (including the adipose fin) sometimes with a spaced peppering of small round black spots. Dorsal and caudal fins brownish-grey, sometimes with large dark maculae; anal and pelvics black, pectorals maculate or sooty.

Affinities and Diagnosis. If Boulenger's (1911) key is used, specimens of $S$. rnacrops run down to $S$. schall, but if specimens of equal size are compared, the larger eye of $S$. macrops is immediately apparent. Indeed, in $S$. schall of a smaller size the eye is relatively smaller. In other respects, however, the two species are similar. Since our knowledge of characters having phyletic importance in the Mochokidae is so negligible, it seems reasonable to suppose that $S$. schall and $S$. macrops are related. Also, on geographical grounds it appears reasonable to assume this relationahip. Certainly $S$. macrops resembles $S$. schall more closely than it does $S$. victoriae (Lakes Victoria and Kyoga), $S$. frontosU8 (Nile) or S. afrofischeri (Victoria basin), the other species with which it has possible geographical relationship.

\section{CYPRINODONTIDAE}

(Hilgen.), 1888

Two males, $3 \cdot 1$ and $3 \cdot 3 \mathrm{~cm}$. S.L., both adult but of indeterminable gonad state. 
This small and colourful species is known in Uganda from a number of scattered localities near Lake Victoria and in the Soroti district; otherwise its main centre of distribution is in Tanganyika. Notlwbranchius taeniopygus, together with other cyprinodonts has been introduced into dams and drainage ditches as predators on mosquito larvae. Thus, their present distribution in eastern Africa may, to a large extent, be artificial.

\section{CICHLIDAE}

Four species of Tilapia (T. leucosticta [f.3], T. zillii [f.2], T. variabilis [f.1] and $T$. galilaea [f.6]) are represented in this collection. The most interesting records are those of $T$. leucosticta (which is otherwise restricted to Lakes Edward and Albert and has not been recorded from the Nile or any other fluviatile habitat) and $T$. variabilis, endemic to the Victoria- Kyoga basin.

Unfortunately we cannot be certain that the Aswa Tilapia are not recent introductions as escapes from local dams which are stocked with both these species. Likewise, $T$. zillii and $T$. galilaea could be either natural or introduced elements.

Less suspicion falls on the Haplochrornis species from this area. Two of the foul' species present $(H$. wingatii and $H$. multicolor) occur in neighbouring areas (including the Nile) and could well be indigenous. The two other species seem to be beyond suspicion, since one is an undescribed species and the other is probably undescribed.

\section{HAPLOCHROMIS CANCELLUS sp. n.}

Description based on the holotype and unique specimen, an immature female 8.6 cm. S.L., (Brit. Mus. (Nat. Hist.) reg. no. 1961.12.1.355).

Depth of body 34.8 per cent of standard length, length of head 32.5 per cent. Dorsal head profile very gently curved and sloping at an angle of $c a .40^{\circ}$.

Preorbital depth 21.4 per cent of head, least interorbital width $26 \cdot 1$ per cent, length of snout 35,7, diameter of eye 32 per cent, depth of cheek 16 per cent. Caudal peduncle 16.3 per cent of standard length, 1.4 times as long as deep.

Mouth horizontal, lips somewhat thickened. Jaws equal anteriorly, the lower 32 per cent of head and 1.5 times as long as broad. The posterior tip of the maxilla reaches a point slightly posterior to the nostril.

Gillrakers relatively slender, twelve on the lower part of the first arch, the 10 wermost four rakers reduced.

Scales ctenoid, 35 in a midlateral series; upper lateral line with 27 scales and extending on to the anterior part of the caudal peduncle, lower lateral line with 15 scales, the first of which lies in the vertical from the last spinous dorsal ray. There are five and a half scales between the lateral line and the dorsal origin and 6 between the pelvic and pectoral fins.

Fins. Dorsal with XVII 10 rays, anal with III 8, the spines stout. Pectoral fin length 25 per cent of standard length. Caudal fin damaged but probably rounded; the rays, especially the median pair, stout. At least the basal two-thirds of the fin is covered with small scales. 
Teeth. The outer series in both jaws is composed of relatively coarse, moveably implanted teeth, numbering 42 in the upper jaw. Anteriorly, the teeth are almost equally bicuspid (see Fig. 1) and the crowns are bluntly square; posterolaterally in the upper jaw the teeth are more unequally bicuspid. In the lower jaw, the outer series does not extend posterolaterally, but is replaced by a salient of teeth from the inner series. The inner teeth in both jaws are small but broad tricuspids, except posterolaterally in the lower jaw where the outermost row is composed of small and slender, bicuspids. The tricuspids have the three cusps almost, equally developed, so that the median cusp projects but slightly above the level of the lateral cusps. There are four rows of inner teeth in the upper jaw and 3, becoming 4 posterolaterally, in the lower jaw.

Osteology. The apophysis for the upper pharyngeal bones is typically Haplochromis, and there is a well-developed apophysis on the third vertebra. The lower pharyngeal bone is stout, and triangular in outline, with a short anterior blade and a deeply indented transverse margin (Fig. 1). The lower pharyngeal teeth are slender except in the most posterior two rows. The anterior teeth are more clearly bicuspid than the posterior ones and their posterior margins are more concave, giving the teeth an incipient hook-shape. The shape of the teeth changes antero-posteriorly on the bone so that the cusps of the posterior teeth are hook-shaped and the upper third of the tooth is sigmoidal in outline. Finally, the last two transverse rows are composed of simple, stout, erect and unequally bicuspid teeth. The teeth are very numerous and densely packed, there being about 300 teeth in the dentigerous area which measures $6 \mathrm{~mm}$. broad and $3.5 \mathrm{~mm}$. long (measured from the first to last tooth ill the median series). The upper pharyngeal teeth are also fine and numerous, and have markedly hooked crowns.

There is some convergence between pharyngeal tooth form in this species and that found in most Tilapia. However, the anterior cusp in H. cancellus i more marked and the posterior outline of the tooth is less concave. The correspondence between the pharyngeal teeth of this species and those of Pseudotropheus species (Lake Nyasa) is almost exact.

Coloration (after formol fixation). Ground colour light brown, the body and caudal peduncle crossed by about ten, narrow vertical bars, complete on the flanks but interrupted on the caudal peduncle. Two dark bars cross the interorbital region and one crosses the snout to meet the broad, dark lachrymal stripe which runs from the angle of the mouth to the lower margin of the orbit. The dorsal fin is hyaline and densely maculate; all other fins are hyaline.

Food. The entire intestine (which is long and coiled) was filled with finely divided debris, including fine sand grains and a large number of diatom frustules; some undigested filamentous green algae were also present.

Affinities. I fully realize the dangers in describing a new cichlid from a single specimen, but this species is so distinctive that I have no hesitation 

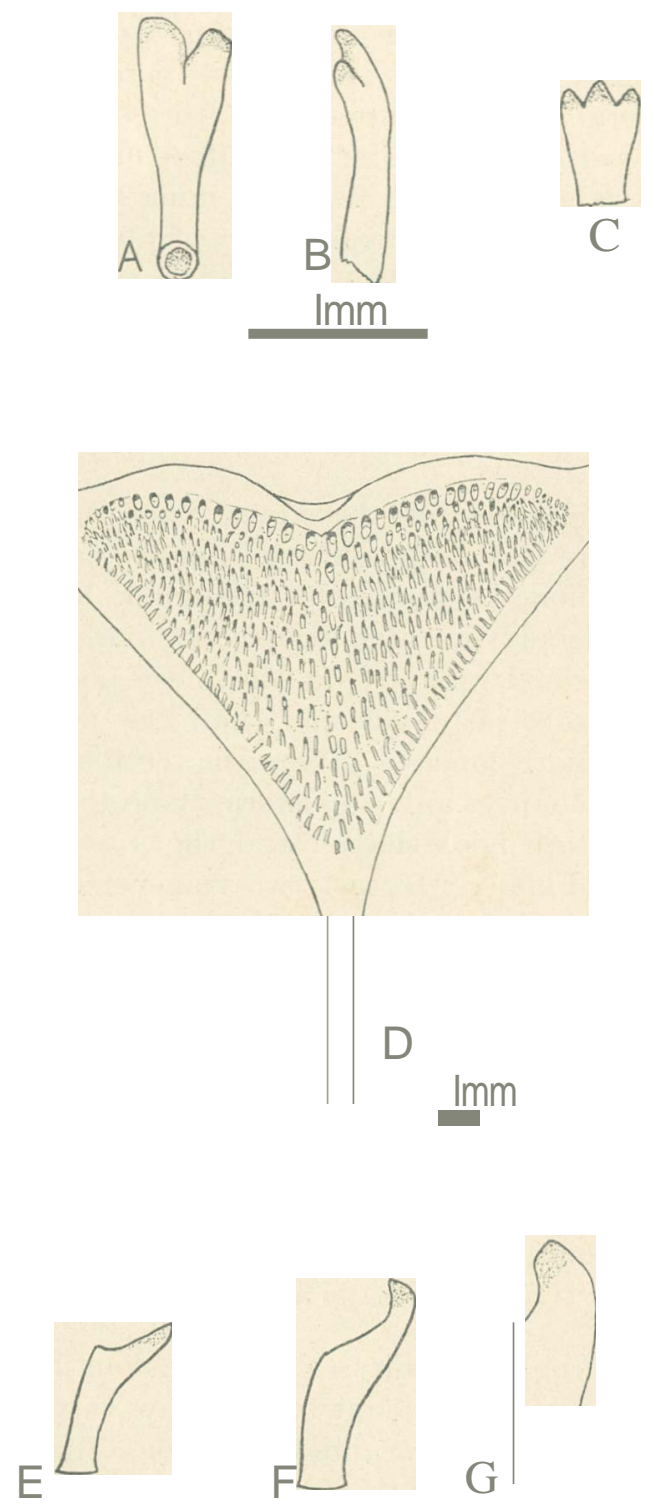

\section{O-Smm}

Fig. I-Dentition of Haplochromis cancellus.

A. Tooth from the anterior part of the outermost row in the dentary (lingual aspect). B. The same in medial aspect. C. Inner tricuspid tooth (lingual aspect). D. Dentigerous surface of the lower pharyngeal bone. E. Anterior pharyngeal tooth (lateral aspect). F. Pharyngeal tooth from the mid-point of an antero-posterior series (lateral aspect). G. Posterior pharyneal tooth (lateral aspect). All thcse pharyngeal teeth are from the median row of the lower pharyngeal bone. 
in basing it on a unique specimen. The most outstanding characters (taken in combination) of $\mathrm{H}$. cancellus are: the "Tilapia"-like (or Pseudotropheuslike) nature of the pharyngeal teeth, the colour pattern, the almost equally bicuspid outer jaw teeth, the extension of the upper lateral line on to the caudal peduncle and the anterior extension of the lower lateral line. Taken singly, any of these characters can be found in some Haplochromis or Haplochromislike species, but I can find no Haplochromis which shows even a partial combination of these features.

In trying to establish the relationships of this species it is natural to look amongst the fluviatile Haplochromis of eastern Africa and amongst the speciesflocks of Lakes Victoria and Kyoga. None of these sources provides a species which might be considered at all closely related to $H$. cancellus. It must, however, be borne in mind that the Haplochromis of Lake Kyoga are still not well known.

Haplochromis cancellus is outstanding when compared with the fluviatile species of Mrica (e.g. H. philander, H. wingatii and $H$. bloyettii) which are, with few exceptions, very generalized species. The exceptions (e.g. $H$. straeleni, $H$. vanderhorsti and $H$. polyacanthus) show adaptations in a' different direction. The first two species have enlarged, crushing pharyngeal teeth and the third a body-form and dentition approaching the genus Orthochromis (Greenwood, 1954). None shows any specialization towards the TilapiaPseuclotropheus type of pharyngeal dentition.

Finally there is the subjectivc impression of "faunal type". The Haplochromis species-flock in each of the major lakes seems to possess a distinct facies. The characters on which this impression is based are varied and numerous, and cannot easily be defined. Some of the more defineable characters are: the densely scaled caudal fins, and the colour patterns of most Lake Nyasa species, as compared with the general lack of such characters in the species from Lakes Victoria and Kyoga. Also, most species from this lake system have lower scale and fin-ray counts than those from Lake Nyasa.

Haplochromis cancellus is certainly not a typical member of the VictoriaKyoga faunal type but seems to be more closely allied to the Nyasa species complex. The dentition, high scale and fin-ray counts, scaled caudal fin and the colour pattern are all found amongst Nyasa species. In fact there is a fairly extensive resemblance between $H$. cancellus and the Nyasan $H$. fenestratus, but the pharyngeal d6ntition of the two species differs, that of $H$. fenestratus being of a coarser and more generalized type.

For the present, $H$. cancellus must occupy a unique and isolated position amongst the fluviatile species of Africa.

\section{Haplochromis sp. indet.}

The fourth Aswa Haplochromis species (also represented by a single specimen) may be an undescribed species. Morphologically it belongs to the elongate, piscivorous predator group, well represented in Lake Victoria by such species as $H$. estor, $H$. mento, $H$. dentex and $H$. squamulatus. It differs from these species in a number of characters (colour pattern, dentition and squamation) but I do not wish to describe it until I have completed my revision of the 
piscivorous predator group in Lake Victoria, and, if possible, obtained more specimens from the Aswa.

\section{MASTACEMBELIDAE}

Mastacembelus victoriae Blgr., 1903

Two immature individuals, 13.5 and 16.3 ems. S.L.

This species is apparently restricted to Lakes Victoria and Nabugabo and to the Victoria Nile; doubtless it also occurs in Lake Kyoga, but its habits and habitat make it a difficult species to capture with conventional gear. Surprisingly, no species of Mastacembelus is recorded from the Nile.

\section{DISCUSSION}

All the specimens listed above came from tributaries of the Aswa river in the Teso district of Uganda. Mr Rhodes informs me (in litt.) that the largest stream was only about six feet across and about a foot deep when the collection was made (April, 1960). He also writes, " It was obvious, however, from the appearance of the grass swamp through which this (the largest) stream meandered that at times of maximum water-level there would be a river about half-a-mile wide".

It is significant that the majority of adult fishes in the collection were in a state of sexual activity. This suggests, that for most species, the sample may represent fishes in their spawning habitats and not necessarily in the habitat they would occupy at other periods. Certainly the area as described by $\mathrm{Mr}$ Rhodes could be one in which these species might spawn during flood seasons (vide Daget [1954] on the spawning habits of these or related species in the upper Niger). The presence of juvenile (but not post-larval) specimens, particularly young Clarias, and other non-breeders is not unusual in spawning streams during and immediately after floods (personal observations in Lake Victoria).

Zoogeographically, one of the most surprising features of the collection is the endemic and phyletically isolated Haplochromis species and the endemic Synodontis macrops. A further peculiarity is the high number of VictoriaKyoga species, both endemics and non-endemics, in relation to the number of truly Nilotic species $(9: 9$ if only Victoria endemics are considered or $14: 9$ Nilotics, if the non-endemic Victora species are included; in both examples the cicWid species are excluded).

Two possible explanations for this phenomenon present themselves; both involve past differences in the Aswa drainage.

The watershed separating the Kyoga from the Aswa drainage systems in the Teso district is relatively slight and could have been less definite in former times, possibly in the nature of a swamp-divide. But, if the drainages were in contact there must have been some unusual form of biological filter, otherwise there would be a greater, and less biased, admixture of the present faunas. In fact if there was such a passage of species, it took place from Kyoga to the Aswa. Six species so far known only from the Victoria-Kyoga drainage basin have gained access to the Aswa, viz. : Labeo victorianus, Barbus cercops 
B. yongei, Mormyrus macrocephalus, Alestes sadleri and Mastacembelus victoriae. In addition there are Barbus paludinosus, B. apleurogramma, B. amphigramma and Barbus (Beirabarbus) radiatus, all species of wide distribution which occur in Lake Victoria but are not recorded from the Nile or Lake Albert.

In sharp contrast, the only Nilotic species in the Aswa also occurring in Victoria-Kyoga is Schilbe mystus a species of very wide distribution in Africa. The eight other Nilotic species (Auchenoglanis occidentalis, Barbus perince, Barilius loati, Alestes nurse, A. macrolepidotus, Hyperopisus bebe, Mormyrus caschive and Gnathonemus cyprinoides) are also of wide distribution but have not penetrated the Victoria-Kyoga system.

Assuming the existence of a swamp divide, I can find no explanation for this apparently differential distribution. The known ecology of many of the species suggests that a swampy region would not provide an insuperable barrier (Daget [1954], Worthington [1929] and personal observations) and anyhow the Victoria-Kyoga endemics with similar habits managed to cross over.

The alternative explanation better fits the biological data. This interpretation involves the assumption that originally the present upper Aswa was part of the Victoria-Kyoga drainage system and that its connection with the Nile is relatively recent, perhaps a result of earth movements which established the outflow of Lake Victoria at Jinja (thought to be about the upper Middle Pleistocene).

If the Aswa once had this direct relationship with the Victoria basin, then the high number of its Victoria-type species is readily explained and the Nilotic fishes could be looked upon as "invaders". On this hypothesis, of course, we must assume that the present watershed has provided an impassable barrier to movement in either direction since the Nile connection was made.

This suggested drainage pattern is at present without geological evidence to support or counter it because the area has not been studied. It gains support from evidence provided by the biology of the fishes concerned and the difficulty of explaining, in the light of these facts, why a larger number of Nilotic species has not crossed from the Aswa into Lake Kyoga.

There the matter must rest until we possess unequivocal geological evidence to eliminate one possibility or the other.

\section{ACKNOWLEDGMENTS}

It gives me great pleasure to thank: the Uganda Game and Fisheries Department for presenting this collection to the British Museum (Natural History) ; Mrs B. M. Hudson who assisted me with the preliminary sorting of the collection and my colleague Dr. Ethelwynn Trewavas for lending me her unpublished notes on the genus Gnathonemus.

\section{REFERENCES}

BOULENGER, G. A. (1911). Catalogue of the fresh-water fishes of Africa. 2. London: Brit. Mus. (Nat. Rist.)

DAGET, J. (1954). Les poissons du Niger superieur. Mém. Inst. Fr. Afr. Noire (lfan-Dakar). No. 36.

GREENWOOD, P. R. (1954). On two species of cichlid fishes from the Malagarazi river (Tanganyika), etc. Ann. Mag. nat. Hist. (12) $7: 401$. 
Greenwood, P. H. (1958). Fishes of Uganda. Kampala: Uganda Society.

Greenwood, P. H. (1959). The characin fishes of Lakes Victoria and Kyoga. Ann. Mag. nat. Hist. (13) $1: 41$.

Greenwood, P. H. (1962). A revision of certain Barbus species (Pisces, Cyprinidae) from East. Central and South Africa. Bull. Brit. Mus. nat. Hist. Zool. 8 No.4: 151-208.

JOB, T. J. (1941). Life-history and bionomics of the spiny eel, Mastacembelus pancalus (Hamilton) with notes on the systematics of the 1\astacembelidae. Rec. Indian Mus. 43: 121.

Worthington, E. B. (1929a). A report on thejishing survey of Lakes Albert and Kyoga. London: Crown Agents.

worthington, E. B. (1929b). New species of fish from the Albert Nyanza and Lake Kyoga. Proc. zool. Soc. Lond. 1929 : 429. 